Article

\title{
Tenure Insecurity, Climate Variability and Renting out Decisions among Female Small-Holder Farmers in Ethiopia
}

\author{
Wisdom Akpalu ${ }^{1, *}$ and Mintewab Bezabih ${ }^{2}$ \\ 1 United Nations University-World Institute for Development Economics Research (UNU-WIDER), \\ University of Ghana, P.O. Box LG 25, Legon-Accra, Ghana \\ 2 The Grantham Institute for Climate Change and the Environment, London School of Economics \\ and Political Science (LSE), London WC2A 2AE, UK; E-Mail: m.bezabih@1se.ac.uk \\ * Author to whom correspondence should be addressed; E-Mail: akpalu @ wider.unu.edu; \\ Tel.: +233-20-961-2485.
}

Academic Editor: Marc A. Rosen

Received: 5 February 2015 / Accepted: 15 June 2015 / Published: 19 June 2015

\begin{abstract}
Land tenure arrangements in Africa are generally skewed in favour of males. Compared to males, female plot owners face complex sets of constraints and systemic high tenure insecurity which culminate in low yields. In order to obtain better returns, some females rent their plots to males, but risk losing the plots to their tenants. A model has been constructed to explain renting-out decisions of female small landholders, an issue largely ignored in the agricultural economics literature. The results, based on a survey of female landholders in Ethiopia, highlight the factors that explain renting-out decisions.
\end{abstract}

Keywords: female headed households; tenure insecurity; productivity; climate variability

\section{Introduction}

Small-holder farmers in Sub-Saharan Africa use rudimentary farming techniques and largely depend on rainfall. As a result, crop yields are persistently low and uncertain. In addition, several empirical studies assessing land productivity in Africa have shown acute and significant differences between male- and female-owned/managed farms, with productivity of female cultivated farms being consistently lower. For example, in a study of the impact of tenure insecurity on land productivity in Eritrea, Tikabo and Holden [1] found that plots owned by female-headed households have lower 
productivity (Following the literature, tenure insecurity entails perceived likelihood of losing a fraction of one's land without the individual's consent (see e.g., [2])). Also, Udry [3] found from a study in Burkina Faso that plots controlled by women were farmed much less intensively than similar plots controlled by their male counterparts within the same households. Similarly, studies from different parts of Ethiopia show the same patterns of lower land productivity of female landowners [4,5].

These differences in land productivity stem from existing norms that inhibit effective utilization of farm inputs by female landholders. As emphasized by Razavi [6], women's effective access to land and its contribution to decent livelihoods are subject to a complex set of ambiguities and difficulties. For example, a taboo exists in Ethiopia against women ploughing with oxen, and some essential agricultural activities are reserved for men [7]. This is notwithstanding the fact that women contribute half (in some cases more than half) of the labour required for agricultural production in Africa $[8,9]$. In addition, it has been found that countries in Africa are generally highly vulnerable to global environmental change and extreme events such as droughts have led to severe farming crises in some of the countries within the last century [10-12]. Female-headed households are particularly vulnerable to drought-induced famines.

In order to obtain higher net benefits from cultivating their plots, some female landholders in Sub-Saharan Africa rent out their plots to their male counterparts for more efficient use. However, socio-cultural and institutional constraints, such as institutions for land allocation, landholding and conflict management, engender the risk of losing plots to male tenants [13]. According to Holden and Tefera [14], females who attempt to use the law in defense of their landholdings are often intimidated, sometimes violently. It has been found that due to the risk of losing plots, female landholders limit their participation in land lease markets. Bellemare [15] has argued that when choosing terms of contract, landholders consider the impact of their choice on the probability of retaining future rights to the rented land.

In this paper, a simple model of a female small landholder has been constructed to explain renting-out decisions. The model compares the benefit from cultivating a plot by the female to the expected benefit from renting it out to a male counterpart. In addition, the conditions under which each option is better than the other have been derived. The theoretical results show that tenure security, high probability of reclaiming a plot if the male tenant attempts to take it, risk aversion, variability of returns due to, say, climate variability (which is proxied by changes in rainfall patterns), and the rate of time preference are positively related to renting-out decisions. On the other hand, high yield or productivity of a plot lowers the chances of renting it out. These findings are illustrated with data from the Amhara region of Ethiopia where the practice is prevalent. In Ethiopia, historically, only adult males have been entitled to land ownership (except within family inheritances) [16]. For married women, gaining access to land is generally linked to marriage, and the rights to plots may be coupled with obligations and other restrictions on use [17-21]. The remainder of the paper is structured as follows. Section 2 traces the history of the land tenure system in Ethiopia. Sections 3 and 4 contain the static and inter-temporal decision model of the female landholder, respectively. Section 5 presents the empirical model and the data, and Section 6 presents and discusses the empirical results. The conclusions are presented in Section 7. 


\section{Background to the Land Tenure System in Ethiopia}

The pre-1975 land tenure system in Ethiopia has been vested in either the rist system, the gult system (private land holding), or the church [22]. The rist system, a communal land tenure system, in which the right to land was not exclusive but shared, implied individuals had usufruct rights to land in a given community on the condition that claimants could establish a direct line of descent from the recognized original holder of the land. Distribution of land within the rist system was based on the principle of equality, with the land allocated by lottery after being divided into parcels according to quality, making it fairly egalitarian [12,22]. The individual's rights to land under this system were not transferable to others through sale or mortgage, although there was room for temporary lease [23]. While the rist system was dominant in the northern half of the country, including Gojam, Tigrai, then Begemder and Semien, then Eritrea, and parts of Wello and Shewa provinces [24], the prevalent system in the southern half of the country was the gult system, which was a private land tenure system. It was characterized by absentee owners, as it was the royal kinsmen or kinswomen who had the gult holdings [25]. The church land, also known as semon land, was owned by the church. During this era, however, women's land rights could be considered inferior to those of men, as independent land ownership by women was rarely recognized, except access to land through marriage or inheritance [16].

The overthrow of the imperial regime in 1975 was also marked by a radical land reform, Proclamation No. 31, 1975, by which all land was made the collective property of the Ethiopian people and an attendant measure that redistributed effective land use rights [24]. While the reform gave usufruct rights to practically all subsistence producers, it also put in place prohibition of land transfer rights through mortgages, leases, sales, or bequests, as well as hiring of labour on the farm [26]. Per the 1975 legislation, spouses enjoyed joint ownership of the land, implying that on paper men and women were entitled to the same land rights. However, women's rights to land depended on marriage and were, in most cases, not registered separately [27].

The replacement of the Derg regime, which was in power from 1975, by the Ethiopian People's Revolutionary Democratic Front in 1991, was also accompanied by the drafting of Article 40 of the Constitution [28], which essentially replicates the previous regime's stance on state ownership of all land. Up to the present, the Constitution guarantees rights of access to land for peasants and pastoralists. It also specifies the rights of individuals to the improvements they make on land, including the right to bequeath, transfer, remove, as well as the right to claim compensation for improvements when the land right expires. However, the mechanisms that ensure these rights and other land issues are left to the regional states [26]. In addition, the ban on land market activity, previously in place, has been lifted, leading to the emergence of active land rental markets [29,30]. One of the most significant changes in the tenure system under the current regime is women's entitlement to land access land through village level redistribution and formal confirmation that land rights are to be granted to men and women [7].

An additional major development in the land tenure system includes the land certification programme that has been going on since 1998. It covers four regions of the country: Tigrai, Amhara, Oromiya and SNNP. More than 5 million certificates have been delivered to farm households since the commencement of the programme [31]. The programme is considered to be highly cost-effective and successful. In particular, the programme is believed to be relatively pro-poor [32]. Moreover, both poorer and less poor households have equal chance of receiving land certificates. In theory, the 
possibility of receiving a land certificate increased the perception of tenure security for both men and women [14] (Holden et al. [33] show how more secure land ownership increased female participation in the land lease market).

\section{The Theoretical Model}

Consider a female landholder who has the option of tilling her plot or renting it out to a male tenant on a shared contract basis. If she chooses the former, she obtains an expected net benefit $m$ plus a normally distributed stochastic margin of $\varepsilon$, where $\varepsilon \sim N\left(0, \sigma_{\varepsilon}^{2}\right)$ (The purpose of the paper is to analyse the pre-certification impacts of tenure insecurity, with emphasis on the role of climate change. The impact of the certification programme in land market participation is covered in other studies [13]). The stochastic term is an index capturing variation in productivity due to changes in environmental conditions (i.e., climate variability). Since the 1980s, both average and minimum temperatures in Ethiopia have increased by $0.2{ }^{\circ} \mathrm{C}$ per decade. Although precipitation across the country has remained fairly constant within the period, its spatial variability has been high. The increasing temperature, high variance of precipitation, and extreme climatic events have negative effects on food security. The landholder's expected utility function is $E v(m+\varepsilon)$, where $E$ is the expectation operator and $v$ signifies a utility function. On the other hand, if the plot is rented out, she obtains an additional net benefit $\beta \geq 0$ but with the probability $(1-\pi) \in(0,1)$ of losing the plot (We have assumed that the extra benefit from renting out (i.e., $\beta$ ) is known a priori. Indeed, this assumption could be relaxed to make the benefit partly stochastic if there is the possibility of shirking (or engaging undesired behavior) on the part of the tenant. This will lower the deterministic part of the benefit and decrease the decision to rent out, all else being equal.). In addition, she incurs litigation cost assumed to be of the form $\alpha v(m)$ if the tenant attempts to seize the plot and she attempts to reclaim it (Note that the litigation cost may include psychological and emotional cost, hence the assumption that it is a fraction of the utility from the deterministic net benefit). Furthermore, let the probability of successfully reclaiming the plot given that the female landholder fights be $\rho \in(0,1)$.

Note that in the absence of the risk of losing the plot (i.e., $\pi=1$ ) and the solution to the problem is simply a corner solution: all female landholders will put out their plots for rent. On the other hand, the solution becomes less trivial if there is a non-negligible risk of losing a rented out plot $(i . e ., \pi \in(1,0)$ ). In the subsequent subsections, we present a simple static (i.e., one period) model for the problem followed by an inter-temporal version which accounts for time discounting.

\subsection{The One-Period (Static) Problem}

Suppose a female landholder contemplates renting out her plot to a male tenant for only one period and also decides a priori not to fight if the tenant seizes the plot at the end of the farming season. She will be indifferent between renting it out and farming it if Equation (1) holds:

$$
E v(m+\varepsilon)=\pi E v(m+\beta+\varepsilon)
$$


where the left hand and right hand sides are the expected indirect utility from own cultivation and from renting out the plot, respectively. A second and first order Taylor expansion of the left and right hand sides, respectively, around $m$ gives

$$
v(m)+0.5 \sigma^{2} v^{\prime \prime}(m) \approx \pi\left(v(m)+\beta v^{\prime}(m)\right)
$$

Let $\eta(m)=\frac{v^{\prime}(m) m}{v(m)}$ be the elasticity of marginal utility of income, and $\theta(m)=-\frac{v^{\prime \prime}(m)}{v^{\prime}(m)}$ be absolute risk aversion. Solving for $\beta$ from Equation (2) gives:

$$
\beta \approx\left(\frac{1-\pi}{\pi}\right) \frac{m}{\eta(m)}-\left(\frac{0.5 \sigma^{2}}{\pi}\right) \theta(m)
$$

Equation (3) stipulates that the landholder will be indifferent between renting out the land and farming it if the extra benefiting obtainable from renting it (i.e., $\beta$ ) balances the value of the risk of losing the plot (i.e., the right hand side). Conversely, she will rent out (not rent out) if the left hand side is greater (lesser) than the right hand side. Now suppose the female landholder decides to fight back. Equation (1) becomes

$$
E v(m+\varepsilon)=\pi E v(m+\beta+\varepsilon)+(1-\pi) E(\rho v(m+\beta+\varepsilon)-\alpha v(m))
$$

Again, the second and first order Taylor expansion of the left hand side and right hand side of Equation (4), respectively, around $m$ is:

$$
v(m)+0.5 \sigma^{2} v^{\prime \prime}(m) \approx(\pi+(1-\pi) \rho)\left(v(m)+\beta v^{\prime}(m)\right)-\alpha(1-\pi) v(m)
$$

The corresponding equation to Equation (3) is:

$$
\beta \approx\left(\frac{(1-\pi)(1+\alpha-\rho)}{(1-\pi) \rho+\pi}\right) \frac{m}{\eta(m)}-\left(\frac{0.5 \sigma^{2}}{(1-\pi) \rho+\pi}\right) \theta(m)
$$

\subsection{Comparative Static Analysis}

We investigate the effect of a change in climate variability, the risk of losing the plot and the probability of retaining the plot if the female landholder fights, the marginal cost of fighting to retain the plot, and risk preference (i.e., $\alpha, \sigma_{\varepsilon}^{2}, \pi, \rho$, and $\theta$ ) on the renting out decision. The following first order derivatives are obtained:

$$
\begin{gathered}
\frac{\partial \beta}{\partial \alpha} \approx\left(\frac{1-\pi}{(1-\pi) \rho+\pi}\right) \frac{m}{\eta(m)}>0 \\
\frac{\partial \beta}{\partial \sigma^{2}} \approx-\frac{0.5}{(1-\pi) \rho+\pi} \theta(m)<0
\end{gathered}
$$




$$
\begin{gathered}
\frac{\partial \beta}{\partial \rho} \approx-\left(\frac{(1-\pi)\left((1-\pi)(1+\alpha-\rho) \frac{m}{\eta(m)}-0.5 \sigma^{2} \theta(m)\right)}{((1-\pi) \rho+\pi)^{2}}+\frac{(1-\pi) \frac{m}{\eta(m)}}{((1-\pi) \rho+\pi)}\right)<0 \\
\frac{\partial \beta}{\partial \pi} \approx-\left(\frac{(1-\rho)(1-\pi)(1+\alpha-\rho) \frac{m}{\eta(m)}-0.5 \sigma^{2} \theta(m)}{((1-\pi) \rho+\pi)^{2}}+\frac{(1+\alpha-\rho) \frac{m}{\eta(m)}}{((1-\pi) \rho+\pi)}\right)<0 \\
\frac{\partial \beta}{\partial m} \approx \mathrm{A}\left(v^{\prime}(m)\left(v^{\prime}(m)\right)^{-1}-v(m)\left(v^{\prime}(m)\right)^{-2} v^{\prime}(m)\right)-\mathrm{B} \theta^{\prime}(m)>0 \\
\frac{\partial \beta}{\partial \theta} \approx-\left(\frac{0.5 \sigma^{2}}{(1-\pi) \rho+\pi}\right)<0
\end{gathered}
$$

where $A=\frac{(1-\pi)(1+\alpha-\rho)}{(1-\pi) \rho+\pi}$ and $B=\frac{0.5 \sigma^{2}}{(1-\pi) \rho+\pi}$.

From the comparative statics, any parameter that is negatively related to $\beta$ tilts the decision towards renting out the plot and vice versa. We discuss Equation (7a) through Equation (7f) in turns. From Equation (7a), an increase in the marginal cost of litigation, all other things being equal, requires higher incentive (i.e., higher $\beta$ ) in order to rent out the plot. Thus, high litigation cost is a disincentive for renting out. Second, higher risk of returns due to, say, climate variability (i.e., an increase in $\sigma_{\varepsilon}^{2}$ ), increases the likelihood of renting out the plot. Furthermore, lower probability of losing the plot and higher probability of reclaiming the plot (given that the tenant decides to seize renting it), all else being equal, will increase the likelihood of renting it out. Finally, Equation (7f) stipulates that a high degree of risk aversion increases the likelihood of renting out. The importance of risk preferences in the decision to rent out land is also emphasized by other studies. Dubois [34], for example, argues that risk preferences are important factors in the determination of maintaining land fertility, and the landlord's subsequent decision in the choice of land contract.

\section{Inter-Temporal Decision Making and the Role of Discounting}

In this section, we investigate the impact of discounting on renting out decisions. For simplicity, but without compromising generality, assume a two-period decision making process. Suppose the female landholder could farm her plot for two successive periods or rent it out and risk losing it. Furthermore, assume renting stops if the tenant attempts to seize the plot. Thus, the plot is rented out the second period if and only if the tenant "behaves well" in the first period. Let all future benefits and costs be discounted at the rate $r>0$. The female landholder is indifferent between renting out and farming the plot for the two periods if the following condition holds:

$$
E v(m+\varepsilon)+\frac{E v(m+\varepsilon)}{1+r}=E v(m+\hat{\beta}+\varepsilon)+\frac{(\pi+(1-\pi) \rho) E v(m+\hat{\beta}+\varepsilon)-\alpha(1-\pi) v(m)}{1+r}
$$


The second and first order Taylor expansions of the left hand side and right hand side of Equation (8) around $m$ gives

$$
(2+r)\left(v(m)+0.5 \sigma^{2} v^{\prime \prime}(m)\right) \approx(1+(1-\pi) \rho+r+\pi)\left(v(m)+\hat{\beta} v^{\prime}(m)\right)-\alpha(1-\pi) v(m)
$$

Rearranging Equation (9) and solving for $\hat{\beta}$ gives

$$
\hat{\beta} \approx\left(\frac{(1-\pi)(\alpha+1-\rho)}{(1+r+\pi)+(1-\pi) \rho}\right) \frac{m}{\eta(m)}-\left(\frac{(2+r) 0.5 \sigma^{2}}{(1+r+\pi)+(1-\pi) \rho}\right) \theta(m)
$$

In addition to the signs of the comparative static analysis obtained earlier (i.e., Equation (7a) through Equation (7f)), the first order derivative of $\beta$ with respect to the discount rate is:

$$
\frac{\partial \hat{\beta}}{\partial r} \approx-\left(\frac{(1-\pi)(1+\alpha-\rho) m \eta(m)^{-1}-(2+r) 0.5 \sigma^{2} \theta(m)}{((1+r+\pi)+(1-\pi) \rho)^{2}}+\frac{0.5 \sigma^{2} \theta(m)}{((1+r+\pi)+(1-\pi) \rho)}\right)<0
$$

From Equation (11), all else being equal, female landholders who have higher discount rates are more likely to rent out their plots. This is intuitive since farmers with higher discount rates value future benefits less (Note that if the landlord does not fight we have $\left.\tilde{\beta} \approx\left(\frac{1-\pi}{1+r+\pi}\right) \frac{m}{\eta(m)}-\left(\frac{2+r}{1+r+\pi}\right) 0.5 \sigma^{2} \theta(m)\right)$. These results are illustrated empirically in the next section using data on small holder female farmers in Ethiopia.

\section{Empirical Model and Data}

To empirically validate our simple theoretical construct, the dependent variable is treated as a decision variable: rent out or not, and the sample is made up of only female landholders. The empirical model is specified as follows:

$$
\beta_{i}=\left\{\begin{array}{cc}
1 & \text { if } \beta_{i}^{*}=a_{0}+a_{1} \pi_{i}+a_{2} r_{i}+a_{3} m_{i}+a_{4} \sigma_{i}^{2}+a_{5} \theta_{i}+a_{5} \rho_{i}+v_{i}>0 \\
0 & \text { otherwise }
\end{array}\right.
$$

where $\beta_{i}$ is the decision variable, $v_{i}$ is a logistically distributed error term, $a_{1}>0, a_{2}>0, a_{3}<0$, and $a_{4}<0$. Equation (12) is estimated as a simple Logit regression. Below, we present the data and discuss the variables used to proxy from those in the Equation (12).

\section{Data}

The data used for the empirical analysis was collected in 2005 from households in two districts of the Amhara National Regional State, a region that encompasses part of the Northern and Central Highlands of Ethiopia. The East Gojjam Zone is a fertile plateau receiving good average rainfall while the South Wollo zone is characterized by degraded hill side plots receiving lower and highly erratic rainfalls. The sampling technique used is stratified random sampling where zones and kebeles were picked by the researchers such that they represent agro-ecological variability in the region. Then 120 households from each kebele was randomly selected (kebele is the smallest administrative unit, similar to a ward, within Ethiopia). The sample size is 733 female headed households. Table 1 present 
definitions of the variables used in the regression analysis and the descriptive statistics. The data consists of socioeconomic characteristics of the respondents and physical characteristics of plots. From the table, the dependent variable "renting out" indicates 17.6 percent of the females rented out their plots.

Table 1. Description of variables used in the regressions.

\begin{tabular}{|c|c|c|c|}
\hline Variable & Variable Description/Definition & Mean & Std. Dev. \\
\hline Rented Out & $\begin{array}{l}\text { A dummy variable indicating } \\
\text { whether the plot is rented out }(1=\text { rented out; } 0=\text { not })\end{array}$ & 0.175552 & 0.380613 \\
\hline Age of Respondent & This is a continuous variable & 52.27000 & 16.40000 \\
\hline Risk Preference & Experimental risk measure & 5.049486 & 1.152152 \\
\hline Rate of time preference & Experimental rate of time preference measure & 1.098229 & 0.438124 \\
\hline Number of male adults per hectare & Adult male in the household per hectare & 2.180287 & 7.679818 \\
\hline Number of livestock per hectare & Livestock ownership in the household per hectare & 5.342999 & 35.74035 \\
\hline Soil type (colour) of parcel: black & Black soil in plot $(1=$ black; $0=$ not black $)$ & 0.440559 & 0.496702 \\
\hline Soil type (colour) of parcel: red & Red soil in plot $(1=$ red; $0=$ not red $)$ & 0.498502 & 0.500248 \\
\hline Soil type (colour) of parcel: white & Grey, sandy or white in plot $(1=$ other; $0=$ not not other $)$ & 0.021978 & 0.146685 \\
\hline Slope of parcel: meda & Flat plot $(1=$ flat; $0=$ not flat $)$ & 0.676471 & 0.468045 \\
\hline Slope of parcel: dagetama & Medium sloped plot $(1=$ medium; $0=$ not medium $)$ & 0.219165 & 0.413877 \\
\hline Soil quality of parcel: lem & Fertile plot $(1=$ fertile; $0=$ not fertile $)$ & 0.497996 & 0.500247 \\
\hline Soil quality of parcel: lemtef & $\begin{array}{l}\text { Medium fertile plot }(1=\text { medium fertile; } \\
\qquad 0=\text { not medium fertile })\end{array}$ & 0.365732 & 0.481876 \\
\hline Average Summer Rainfall & Annual summer mean rainfall & 128.1254 & 40.12047 \\
\hline Experience Land Related Conflict & $\begin{array}{l}\text { Dummy variable for whether the household has } \\
\text { experienced land related conflict in the past } \\
\qquad(1=\text { yes; } 0=\text { no })\end{array}$ & 0.20864 & 0.406523 \\
\hline Expecting Change in land Holdings & $\begin{array}{l}\text { Dummy variable for whether the household has } \\
\text { experienced a change in land in the past }(1=\text { yes; } 0=\text { no })\end{array}$ & 0.355699 & 0.478945 \\
\hline Long Term Average Summer Rainfall & Long term summer mean rainfall & 178.6941 & 43.41238 \\
\hline
\end{tabular}

The variable "risk preference" (i.e., $\theta_{i}$ ) is generated from a choice experiment consisting of six choice sets (see Appendix 1a). Each choice set consists of hypothetical gain and loss of 50 percent probability each from a given farm. The hypothetical farm could make gains and losses ranging from Ethiopian Birr (Br.) 0 to 400, with the specific values chosen to reflect the farmers' annual incomes. Accordingly, Br. 0 represent extreme risk aversion while gains and losses of Br. 200 represent neutral risk preferences, with the rest of the risk aversion categories ranging between these two extremes. The mean risk classification value is 5.05 , with a relatively low standard deviation of 1.15 , signifying severe risk aversion (see Appendix 1a).

Following the procedure in Yesuf and Bluffstone [35], an experiment was set up to elicit the rate of time preference $\left(i . e ., r_{i}\right)$. Each respondent was presented with the choice of receiving a given amount of money on a given day (a more immediate, smaller payment) or an alternative amount one year later (a higher amount) (see Appendix 1b). The choice sets were arranged in such a way that the difference between the present and future amounts was randomly sequenced. All choice sets offered choices between $\mathrm{Br}$. 50 to be received today and an amount ranging between $\mathrm{Br}$. 65 and $\mathrm{Br}$. 195 to be received 
in one year. The choice set with the largest difference was given by an early reward of $\mathrm{Br} .50$ and a later reward of Br. 195. A switch from the choice of an early reward to a choice of delayed reward provides a measure of the rate of time preference for each respondent. The instantaneous individual discount rate is computed as $r_{i}=\log \left(\psi_{2} / \psi_{1}\right)$, where $\psi_{2}$ is the amount provided after 12 months, and $\psi_{1}$ is the amount provided instantaneously. The computed average rate of time preference is 109.8, which is high but close to the median value obtained by Yesuf and Bluffstone [35], but lower than the mean value of 131 obtained among artisanal fishers in Ghana [36]. The stochastic component of yield or earnings $\left(\right.$ i.e., $\sigma_{i}^{2}$ ) is attributable to climate variability. This is represented mainly by rainfall in the summer and major rainy seasons. The average and long-term summer rainfalls are $128 \mathrm{~mm}$ and $179 \mathrm{~mm}$, with standard deviations of 40 and 43 , respectively.

The tenure security or perceived probability of retaining rented out plot $\left(i . e ., \pi_{i}\right)$ is proxied by the number of female farmers who experienced conflicts in the past, and whether or not the respondent expected any change(s) in her land holdings resulting from land redistribution. Thus, regarding the former, all else being equal, a farmer who experienced a conflict in the past pertaining to her landholding will be more likely to perceive a higher likelihood of losing the land if it is rented out. Approximately $21 \%$ of the respondents experienced land related conflicts and $36 \%$ expected their land holdings to change. Also, the number of household adult males per hectare of land holdings is used as a proxy for the probability of winning the land back if the tenant attempts to confiscate it (i.e., $\left.\rho_{i}\right)$. On average, there were two adults to each hectare. Secure property rights are considered an important catalyst for leasing out decisions, the argument being that landlords can only be confident of leasing out land if the benefits of renting out land, in terms of increased productivity are larger than the risk of expropriation [22,37,38]. Furthermore, average yield potential or productivity of plots $\left(i . e ., m_{i}\right)$ is represented by physical characteristics of the plot which include plot fertility, plot slope, and soil color; and the number of livestock per hectare of the plot. The soil types identified are white, black and red; and each hectare of plot has five livestock on the average but with a high standard deviation, which is about six times the mean.

\section{Results and Discussion}

As noted earlier, the empirical equation estimated is a simple Logit regression with the decision to rent out or not as the dependent variable. Table 2 contains the regression results presented as regression (1) and (2). The two regressions are similar except that each contain either of the variable "long term average summer rainfall" or "average summer rainfall", which are collinear. The partial average elasticities (PAEs) are calculated using the "margeff" routine in Stata 12. The likelihood ratio tests indicate each of the two regression lines is a good fit $(p<0.001)$, and the pseudo R-squared of 0.11 implies about 11 per cent of the variability of the logarithm of the odd ratio has been explained by each regression line, which is expected for a cross-sectional data of this nature. 
Table 2. Determinants of renting out decision among female land holders in Ethiopia.

\begin{tabular}{|c|c|c|c|c|}
\hline \multirow[b]{2}{*}{ Variable } & \multicolumn{2}{|c|}{ Regression 1} & \multicolumn{2}{|c|}{ Regression 2} \\
\hline & Coefficients & $\begin{array}{l}\text { Partial Average } \\
\text { Elasticity (PAE) }\end{array}$ & Coefficients & PAE \\
\hline \multirow[t]{2}{*}{ Risk Preference } & $0.265 * * *$ & 0.043 & $0.281 * * *$ & 0.045 \\
\hline & $(0.098)$ & & $-(0.102)$ & \\
\hline \multirow[t]{2}{*}{ Rate of Time Preference } & -0.193 & & -0.274 & \\
\hline & $-(0.230)$ & & $-(0.223)$ & \\
\hline \multirow[t]{2}{*}{ Age of Respondent } & $0.018 * * *$ & 0.003 & $0.018 * * *$ & 0.003 \\
\hline & $-(0.005)$ & & $-(0.005)$ & \\
\hline \multirow[t]{2}{*}{ Number of male adults per hectare of land holdings } & -0.036 & & -0.039 & \\
\hline & $-(0.080)$ & & $-(0.078)$ & \\
\hline \multirow[t]{2}{*}{ Number of livestock per hectare } & $-0.170 * *$ & -0.026 & $-0.169 * *$ & -0.026 \\
\hline & $-(0.081)$ & & $-(0.080)$ & \\
\hline \multirow[t]{2}{*}{ Soil type (colour) of parcel: black } & 0.315 & & 0.296 & \\
\hline & $-(0.424)$ & & $-(0.420)$ & \\
\hline \multirow[t]{2}{*}{ Soil type (colour) of parcel: red } & 0.162 & & 0.145 & \\
\hline & $-(0.426)$ & & $-(0.419)$ & \\
\hline \multirow[t]{2}{*}{ Soil type (colour) of parcel: white } & -0.453 & & -0.445 & \\
\hline & $-(0.793)$ & & $-(0.807)$ & \\
\hline \multirow[t]{2}{*}{ Slope of parcel: meda } & -0.438 & & -0.435 & \\
\hline & $-(0.362)$ & & $-(0.375)$ & \\
\hline \multirow[t]{2}{*}{ Slope of parcel: dagetama } & -0.487 & & -0.462 & \\
\hline & $-(0.375)$ & & $-(0.387)$ & \\
\hline \multirow{2}{*}{ Soil quality of parcel: lem } & -0.385 & & -0.314 & \\
\hline & $-(0.303)$ & & $-(0.314)$ & \\
\hline \multirow[t]{2}{*}{ Soil quality of parcel: lemtef } & -0.25 & & -0.202 & \\
\hline & $-(0.294)$ & & $-(0.305)$ & \\
\hline \multirow[t]{2}{*}{ Long Term Average Summer Rainfall } & $0.008 * * *$ & 0.001 & & \\
\hline & $-(0.003)$ & & & \\
\hline \multirow[t]{2}{*}{ Experience Land Related Conflict (1/0) } & -0.057 & & -0.169 & \\
\hline & $-(0.229)$ & & $-(0.237)$ & \\
\hline \multirow[t]{2}{*}{ Expecting Change in land Holdings (1/0) } & $-0.561 * *$ & -0.084 & $-0.509 * *$ & -0.076 \\
\hline & $-(0.220)$ & & $-(0.221)$ & \\
\hline \multirow[t]{2}{*}{ Average Summer Rainfall } & & & $0.009 * * *$ & 0.001 \\
\hline & & & $-(0.003)$ & \\
\hline \multirow[t]{2}{*}{ Constant } & $-3.660 * * *$ & & $-3.356 * * *$ & \\
\hline & $-(1.118)$ & & $-(1.020)$ & \\
\hline Log Likelihood & -335.97 & & -332.24 & \\
\hline Pseudo R-squared & 0.11 & & 0.11 & \\
\hline \# of Observations & 713 & & 709 & \\
\hline
\end{tabular}

Note: $* * * p<0.01, * * p<0.05, * p<0.1$.

The coefficient of the variable "Risk preference" is statistically significant at the 1 per cent level and positively related to renting-out decisions, as predicted by the theoretical model. The corresponding PAE indicates that, all else being equal, the probability of renting out increases by 0.043 
if the risk preference increases by one unit. This finding lends support to a recent study which found that a high degree of risk aversion is associated with shorter contract durations in Ethiopia [39].

Second, although the soil characteristics do not appear to influence renting-out decisions, the number of livestock per hectare does, with a coefficient that is significant at the 1 per cent level. The coefficient has the expected sign and indicates that increasing the number of livestock by one unit decreases the probability of renting out by 0.026 . Thus, an increase in livestock is expected to increase yield and thereby discourage the farmer from renting out her plot. This could possibly be due to oxen holdings and/or wealth status effect. Local traditions and cultures forbids females directly engaging in oxen ploughing but they are able to engage the services of their male counterpart if the females own oxen.

Third, farmers who expected their landholdings to change are less likely to rent out, with the coefficient of the variable being significant at the 5 per cent level. This is consistent with the theoretical prediction. The PAE indicates that those who expect such changes are 0.08 per cent less likely to rent out their plots. Fourth, climate variability, which is captured by summer rainfall, increases the probability to rent out, albeit weakly. From the coefficient, for example, a $10 \mathrm{~mm}$ increase in the average summer rainfall increases the probability of renting out by 0.001 .

Furthermore, households with older heads are more inclined to rent out plots. This appears to suggest that older household heads obtain lower average earnings when they cultivate the plot themselves. Specifically, from the PAE, a household head who is 10 years older than her counterpart will have 0.03 higher probability of renting out her plot. It is noteworthy that the average age is quite high (52 years), since the life expectancy for females in Ethiopia is 62 years. Surprisingly, the rate of time preference variable obtained through the experiment is not statistically significant in explaining renting-out decisions. With poor functioning formal rural credit markets in many developing countries [40] it is expected that farmers with very high personal discount rates will be more likely to rent out their plots. Perhaps the variable is not statistically significant because the rates are generally high for all farmers with low variance. Finally, all else being equal, there is no significant difference in renting-out decisions between households that have experienced land-related conflict in the past (conflict) and their counterparts who have not.

\section{Conclusions}

Tenure insecurity remains a major issue among female landholders in Ethiopia and elsewhere in Sub-Saharan Africa. Land reform programmes that explicitly aimed at enhancing women's land rights are desirable as women contribute about half of the labour force in agriculture on the continent. Thus, minimising the complex set of constraints inhibiting land use and transfer rights among women will improve land productivity, reduce poverty and gender inequality, and enhance economic growth. Since males farm their plots much more intensively than their female counterparts, the female landholders could rent out their plots to male tenants for higher returns but then incur the risk of losing their land. This research has found that, in theory, female landholders will be less likely to rent out their plots if the risk of losing a plot is high, land productivity is high, marginal cost of litigation is high, variability in climate is low, and the absolute risk aversion is low. In addition, in an inter-temporal setting, farmers who are impatient or uncertain about the future are more likely to rent out their plots, all else being equal. 
The empirical results of this study based on data on female landholders from Ethiopia largely support the theoretical predictions. Specifically, risk preference, average productivity of the plot (proxied by livestock holdings), variability of yield (proxied by average rainfall) and the risk of losing the plot (proxied by expected change in land holding) were found to be statistically significant. Although discount rates elicited through an experiment were not significant, females who were relatively older were more likely to rent out their plots as they are more likely to care less about the future or more likely to desire bigger gains now from renting their plots out. Thus, in addition to improving tenure security, any policy that increases the livestock holdings (including oxen holdings) of the female small landholders could empower them to cultivate their own plots effectively, rather than renting them out. An obvious way to improve tenure security is by reducing the cost of farm land adjudication, which may make it easier for landholders to rent out their plots and obtain better yields. Also, since older females are also more likely to rent out their plots and also lose them, public policy must be designed to protect them.

In a nutshell, improving tenure security for female landholders would obviously enhance their engagement in the land rental market and enhance their welfare through increased productivity. A complementary policy option is to provide financial support to increase their livestock holdings, which also leads to improved productivity and welfare.

\section{Acknowledgments}

Wisdom Akpalu is the corresponding author. The authors wish to express their gratitude to Sida (Swedish International Development and Cooperation Agency) for the data used for this research. We would also like to express our profound gratitude to two anonymous referees for their thoughtful comments.

\section{Author Contributions}

Both authors contributed equally to the research design. Wisdom Akpalu formulated the theoretical model and did the general write-up. Mintewab Bezabih did the regression analysis and discussion of the empirical results, as well as proofread the manuscript. Both authors have read and approved the final manuscript.

\section{Conflicts of Interest}

The authors declare no conflict of interest.

\section{Appendix 1a}

\section{The Structure of the Risk Experiment}

We would now like to know how you would choose between different agricultural plots with different characteristics. Imagine that you have two plots. The production on the plots differs depending on if the rains are good or bad. There are equal chances (50 per cent) of good or bad rains. 
(Exemplify with a coin that is tossed-head represents a bad harvest and tails represents a good harvest.) (Enumerator: Circle the number for the choice made for each pair.)

\begin{tabular}{|ccccccc|}
\hline & $\begin{array}{c}\text { Bad } \\
\text { Harvest }\end{array}$ & $\begin{array}{c}\text { Good } \\
\text { Harvest }\end{array}$ & $\begin{array}{c}\text { Expected } \\
\text { Mean }\end{array}$ & Spread & $\begin{array}{c}\text { CPRA } \\
\text { Coefficient }\end{array}$ & $\begin{array}{c}\text { Risk } \\
\text { Classification }\end{array}$ \\
\hline Choice Set 1 & 100 & 100 & 100 & 0 & $+\infty-7.5$ & Extreme \\
Choice Set 2 & 90 & 180 & 135 & 90 & $7.5-2.0$ & Severe \\
Choice Set 3 & 80 & 240 & 160 & 160 & $2.0-0.812$ & Intermediate \\
Choice Set 4 & 60 & 300 & 180 & 240 & $0.812-0.316$ & Moderate \\
Choice Set 5 & 20 & 360 & 190 & 360 & $0.316-0.0$ & Slight \\
Choice Set 6 & 0 & 400 & 200 & 400 & $0.0--\infty$ & Neutral \\
\hline
\end{tabular}

\section{Appendix 1b}

\section{The Structure of the Rate of Time Preference Experiment}

We would like to ask you how you feel about money today compared with money exactly one year from now. Imagine that you can choose between receiving money today and a larger sum of money exactly one year from now. For example if you have a choice between receiving $50 \mathrm{Br}$. (Ethiopian Birr (ETB)) and 65 Br. in a year's time, which would you choose?

\begin{tabular}{|ccc|}
\hline Choice set 1 & 50 ETB now & 65 ETB after 12 months \\
Choice set 2 & 50 ETB now & 80 ETB after 12 months \\
Choice set 3 & 50 ETB now & 105 ETB after 12 months \\
Choice set 4 & 50 ETB now & 130 ETB after 12 months \\
Choice set 5 & 50 ETB now & 160 ETB after 12 months \\
Choice set 6 & 50 ETB now & 195 ETB after 12 months \\
\hline
\end{tabular}

\section{References}

1. Tikabo, M.O.; Holden, S.T. Land Contract Choice: Poor Landlords and Rich Tenants—Evidence from the Highlands of Eritrea; Norwegian University of Life Sciences, Department of Economics and Social Sciences: Ås, Norway, 2003 Available online: http://www.chr.up.ac.za/chr_old/ indigenous/documents/Eritrea/Report/Land\%20Tenure\%20in\%20the\%20Highlands\%20of\%20Eri trea\%20Economic\%20Theory.pdf (accessed on 17 June 2015).

2. Holden, S.; Yohannes, H. Land Redistribution, Tenure Insecurity, and Intensity of Production: A Study of Farm Households in Southern Ethiopia. Land Econ. 2002, 78, 573-590.

3. Udry, C. Gender, Agricultural Production, and the Theory of the Household. J. Polit. Econ. 1996, 104, 1010-1046.

4. Holden, S.; Shiferawand, B.; Pender, J. Market Imperfections and Land Productivity in the Ethiopian Highlands. Am. J. Agric. Econ. 2001, 52, 53-70.

5. Holden, S.; Bezabih, M. Gender and Land Productivity on Rented Land in Ethiopia. In The Emergence of Land Markets in Africa: Impacts on Poverty, Equity and Efficiency; Holden, S.T., Otsuka, K., Place, F., Eds.; Resources for the Future: Washington, DC, USA, 2008. 
6. Razavi, S. Liberalisation and the Debates on Women's Access to Land. Third World Q. 2007, 28, 1479-1500.

7. Gebreselassie, M. Women and Land Rights in Ethiopia; Relief Society of Tigray and the Development Fund: Mekelle, Ethiopia, 2005.

8. Frank, E. Gender, agricultural development and food security in Amhara, Ethiopia: The contested identity of women farmers in Ethiopia. Available online: http://pdf.usaid.gov/pdf_docs/ PNACG552.pdf (accessed on 17 June 2015).

9. Kevane, M.; Gray, L. A Woman's Field is Made at Night: Gendered Land Rights and Norms in Burkina Faso. Femin. Econ. 1999, 5, 1-26.

10. Aklilu, A.; Alebachew, A. Assessment of Climate Change-Induced Hazards, Impacts and Responses in the Southern Lowlands of Ethiopia; Forum for Social Studies (FSS): Addis Ababa, Ethiopia, 2008.

11. Collins, J.M. Temperature Variability over Africa. J. Clim. 2011, 24, 3649-3666.

12. IPCC. Climate Change 2007: Impacts, Adaptation and Vulnerability. Contribution of Working Group II to the Fourth Assessment Report of the IPCC; IPCC: Geneva, Switzerland, 2007.

13. Holden, S.T.; Deininger, K.; Ghebru, H. Tenure insecurity, gender, low-cost land certification and land rental market participation. J. Dev. Stud. 2011, 47, 31-47.

14. Holden, S.T.; Tefera, T. From Being the Property of Men to Becoming Equal Owners? Early Impacts of Land Registration and Certification on Women in Southern Ethiopia; Final Research Report submitted to UN-HABITAT; Shelter Branch, Land Tenure and Property Administration Section: Nairobi, Kenya, 2008.

15. Bellemare, M.F. Insecure Land Rights and Reverse Share Tenancy in Madagascar; Working Paper; Duke University: Durham, NC, USA, 2008.

16. Crummy, D. Land and Society in the Christian Kingdom of Ethiopia; University of Illinois Press: Champaign, IL, USA, 2000.

17. Derman, B.; Odgaard, R.; Sjaastad, E. Conflicts over Land and Water in Africa; James Currey: Oxford, UK, 2007.

18. Dey, J. Gambian Women: Unequal Partners in Rice Development Projects? J. Dev. Stud. 1981, 17, 109-122.

19. Okali, C. Cocoa and Kinship in Ghana: The Matrilineal Akan of Ghana; Kegan Paul International: London, UK, 1983.

20. Goheen, M. Land and the household economy: Woman farmers of the Grassfields today. In Agriculture, Women and Land: The African Experience; Davison, J., Ed.; Westview Press: Boulder, CO, USA, 1988.

21. Yngstrom, I. Women, Wives, and Land Rights in Africa: Situating Gender Beyond the Household in the Debate over Land Policy and Changing Tenure Systems. Oxford Dev. Stud. 2002, 30, $22-40$.

22. Gebreegziabher, Z.; Gebremedhin, B.; Mekonnen, A. Institutions, Sustainable Land Use, and Consumer Welfare: The Case of Forest and Grazing Lands in Northern Ethiopia. Environ. Dev. Econ. 2012, 17, 21-40.

23. Hagos, F.; Pender, J.; Gebreselassie, N. Land Degradation in the Highlands of Tigrai and Strategies for Sustainable Land Management; Socioeconomic Policy Research Working Paper, no. 25; International Livestock Research Institute: Addis Ababa, Ethiopia, 2008. 
24. Nickola, T. The Agricultural Sector in Ethiopia: Organization, Policies and Prospects. In Beyond the Famine: An Examination of Issues behind the Famine in Ethiopia; Penrose, A., Ed.; International Institute for Relief and Development, Food for Hungry International: Geneva, Switzerland, 1988; pp. 99-141.

25. Hussein, J. The Politics of Land Tenure in Ethiopian History: Experience from the South. In Proceedings of the XI World Congress of Rural Sociology, Trondheim, Norway, 25-30 July 2004.

26. Kebede, B. Land Reform, Distribution of Land and Institutions in Rural Ethiopia: Analysis of Inequality with Dirty Data. J. Afr. Econ. 2008, 17, 550-577.

27. Crewett, W.; Bogale, A.; Korf, B. Land Tenure in Ethiopia: Continuity and Change, Shifting Rulers, and the Quest for State Control; CAPRi Working Paper, No. 91; International Food Policy Research Institute: Washington, DC, USA, 2008.

28. Federal Democratic Republic of Ethiopia (FDRE). Constitution of the Federal Democratic Republic of Ethiopia. Available online: http://unpan1.un.org/intradoc/groups/public/documents/ cafrad/unpan004722.pdf (accessed on 17 June 2015).

29. Benin, S.; Pender, J.; Mohamed, A.; Ehui, S. Development of Land Rental Markets and Agricultural Productivity Growth: The Case of Northern Ethiopia. J. Afr. Econ. 2005, 14, 21-54.

30. Pender, J.; Fafchamps, M. Land Lease Markets and Agricultural Efficiency: Theory and Evidence from Ethiopia. Available online: http://www.csae.ox.ac.uk/workingpapers/pdfs/2002-19text.pdf (accessed on 17 June 2015).

31. Bezabih, M.; Holden, S. The Role of Land Certification in Reducing Gender Gaps in Productivity in Rural Ethiopia. Environ. Dev. 2010, 23, 10-23.

32. Deininger, K.; Ali, D.; Holden, S; Zevenbergen, J. Rural Land Certification in Ethiopia: Process, Initial Impact, and Implications for Other African Countries. World Dev. 2008, 36, 1786-1812.

33. Holden, S.; Deininger, K.; Ghebru, H. Impacts of Low-cost Land Certification on Investment and Productivity. Am. J. Agric. Econ. 2009, 91, 359-373.

34. Dubois, P. Moral Hazard, Land Fertility and Sharecropping in a Rural Area of the Philippines. J. Dev. Econ. 2002, 68, 35-64.

35. Yesuf, M.; Bluffstone, R.A. Poverty, Risk Aversion and Path Dependence in Low-Income Countries: Experimental Evidence from Ethiopia. Am. J. Agric. Econ. 2009, 91, 1022-1037.

36. Akpalu, W. Fishing regulations, individual discount rate, and fisherman behaviour in a developing country fishery. Environ. Dev. Econ. 2008, 13, 591-606.

37. Ghebru, H.; Holden, S.T. Factor Market Imperfections and Rural Land Rental Markets in Northern Ethiopian Highlands. In The Emergence of Land Markets in Africa: Assessing the Impacts on Poverty, Equity and Efficiency; Holden, S.T., Otsuka, K., Place, F., Eds.; Resources For the Future Press: Washington, DC, USA, 2008; pp. 74-92.

38. Lunduka, R.; Holden, S.; Øygard, R. Land Rental Market Participation and Tenure Security in Malawi. In The Emergence of Land Markets in Africa: Impacts on Poverty and Efficiency; Holden, S.T., Otsuka, K., Place, F., Eds.; Resources for the Future: Washington, DC, USA, 2008.

39. Beyene, A.D.; Bezabih, M.; Gebreegziabher, Z. Contract Duration under Incomplete Land Ownership Rights: Empirical Evidence from Rural Ethiopia. Available online: http://www.efdinitiative.org/sites/default/files/efd-dp-12-09-2_0.pdf (accessed on 17 June 2015). 
40. Stiglitz, J.E.; Weiss, A.M. Credit Rationing in Markets with Imperfect Information. Am. Econ. Rev. 1981, 1981, 393-410.

(C) 2015 by the authors; licensee MDPI, Basel, Switzerland. This article is an open access article distributed under the terms and conditions of the Creative Commons Attribution license (http://creativecommons.org/licenses/by/4.0/). 